\title{
Land subsidence of coastal areas of Jiangsu Province, China: historical review and present situation
}

\author{
J. Q. Zhu ${ }^{1}$, Y. Yang ${ }^{2}$, J. Yu ${ }^{1}$, and X. L. Gong ${ }^{1}$ \\ ${ }^{1}$ Key Laboratory of Earth Fissures Geological Disaster, Ministry of Land and Resources, Geological Survey of \\ Jiangsu Province, Nanjing, 210018, China \\ ${ }^{2}$ School of Earth Sciences and Engineering, Hohai University, Nanjing, 210098, China
}

Correspondence to: Y. Yang (yy_hhu@ @hu.edu.cn)

Published: 12 November 2015

\begin{abstract}
Surface faults related to land subsidence have been observed in coastal cities, such as Nantong, Yancheng, and Lian Yungang, in Jiangsu Province (CAJS) since the early 1970s. Nowadays, increases flooding and rising sea levels are attributed to subsidence caused by groundwater pumping. In this work we present a brief description of land subsidence in CAJS, we examine the mechanisms of land subsidence induced mainly by groundwater pumping and its evolution and economic implications as well as the implemented measures by the local government to prevent new damage.
\end{abstract}

\section{History and current status of land subsidence in CAJS}

\subsection{Development history of land subsidence}

Before the 1970s, the coastal areas of Jiangsu Province (CAJS) experienced very slight land subsidence (1-2 mm annually), dominated by natural consolidation and settlement of loose soil and rocks (Hu et al., 2004). However, entering the 1980s, large-scale groundwater exploitation began in the cities of Yancheng, Dafeng, and Nantong of Jiangsu Province, leading to a rapid decline of the groundwater table in coastal areas. In the 1990s, as the intensity of groundwater exploitation in the urban districts rose, the issue of land subsidence began to affect the entire region with greater severity (Xue et al., 2005).

In the past decade, from 2005 to 2013, land subsidence of coastal areas began to extend to the north of Yancheng City and to the south of Lianyungang City (Fig. 1). In addition to the surrounding areas of Yancheng City and Dafeng City, the cumulative subsidence of the counties of Guanyun, Guannan, Xiangshui, and Funing exceeded $200 \mathrm{~mm}$, with an annual average subsidence rate of $25 \mathrm{~mm} \mathrm{a}^{-1}$. On the basis of monitoring data from 2005 to 2013, it was found that coastal regions with cumulative subsidence exceeding $200 \mathrm{~mm}$ covered an area of $1.06 \times 10^{4} \mathrm{~m}^{2}$. A subsidence cone was formed cen- tered around Nantong City, Haimen City, and the urban districts of Dafeng, Yancheng, and Rudong City as shown in Fig. 1.

In addition, land subsidence has reached a critical level in the north coastal areas of Dafeng City. The cumulative subsidence in all these regions has exceeded $250 \mathrm{~mm}$, with the exceptions of the southwest areas of Guanyun County, northwest areas of Guannan County, east of Xiangshui County, east of Binhai County, northeast of Sheyang County, and south of Dafeng City. Several land subsidence cones have formed in the urban districts of Nantong City, Haimen City, and Matang Town of Rudong County, which is located in Dongtai City, and the coastal areas to the south of Dongtai. In some of these regions, the cumulative subsidence has also exceeded $250 \mathrm{~mm}$.

\subsection{Current status of land subsidence}

In 2013, both the magnitude and area of subsidence increased at accelerated rate in the northern coastal areas of Jiangsu Province (Fig. 2). The annual subsidence levels in the long, narrow strips on the both banks of the abandoned Yellow River, Guan River, and North Jiangsu Irrigation Canal exceeded $30 \mathrm{~mm}$. The annual subsidence of Yanweigang Town in Lianyungang City at the border between Lianyungang and Yancheng City exceeded $40 \mathrm{~mm}$. The confined aquifer III 


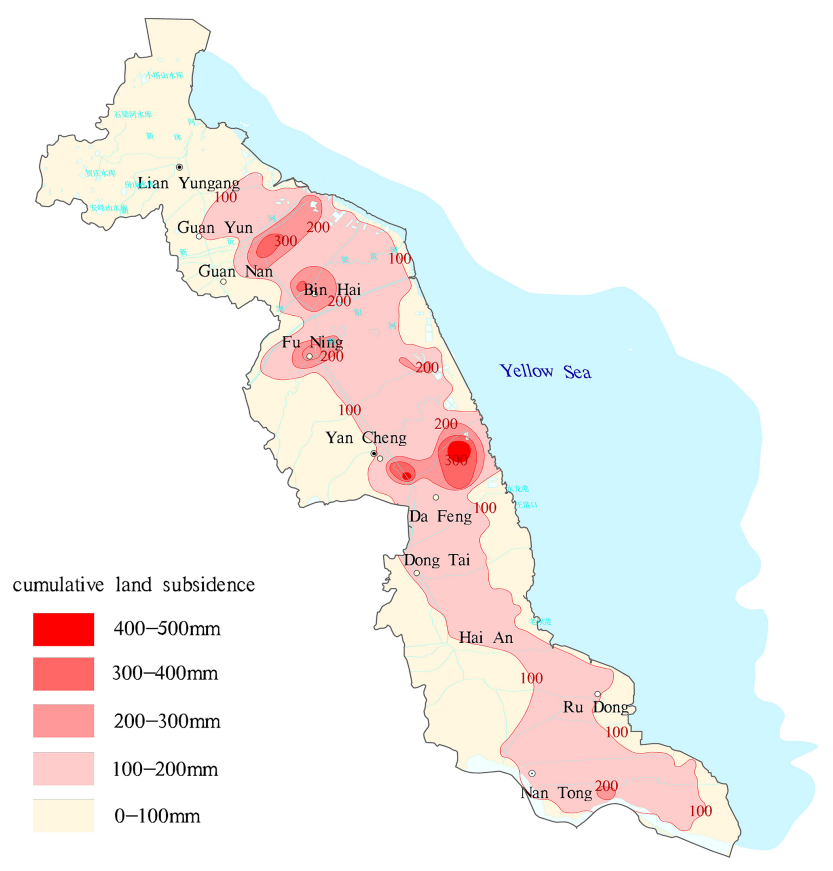

Figure 1. Cumulative land subsidence in CAJS from 2005 to 2013.

was mainly exploited in this region, where the artesian head is above $30 \mathrm{~m}$. This region also suffered from the most serious land subsidence in Jiangsu Province.

Dafeng City and the urban district of Yancheng City showed much earlier signs of land subsidence. Because of effective countermeasures adopted by local water authorities, the decline in the artesian head was reversed to some extent. The water table in the urban district began to be restored, and the land subsidence rate decreased. However, due to the long history of regional subsidence, the subsidence rate in 2013 was still over $15 \mathrm{~mm}$.

\section{Mechanisms of land subsidence development}

Through long-term monitoring and analysis, land subsidence has been found to have the following characteristics: slow progression, persistency, hysteresis, resilience, irreversibility, non-uniformity, and complexity. The factors influencing land subsidence are very complicated, and the degree of land subsidence and the intensity of influential factors vary spatially. The main influential factors are the thickness of loose overlying stratum, aquifer development, groundwater exploitation dynamics, and engineering and construction activities (Xu et al., 2008).

\subsection{Geological conditions as endogenous factors of land subsidence}

Coastal areas usually have thick superficial loose sediment layers, which mainly consist of marine or interactive marine and terrestrial deposits. Sullage-containing, soft-soil lay-

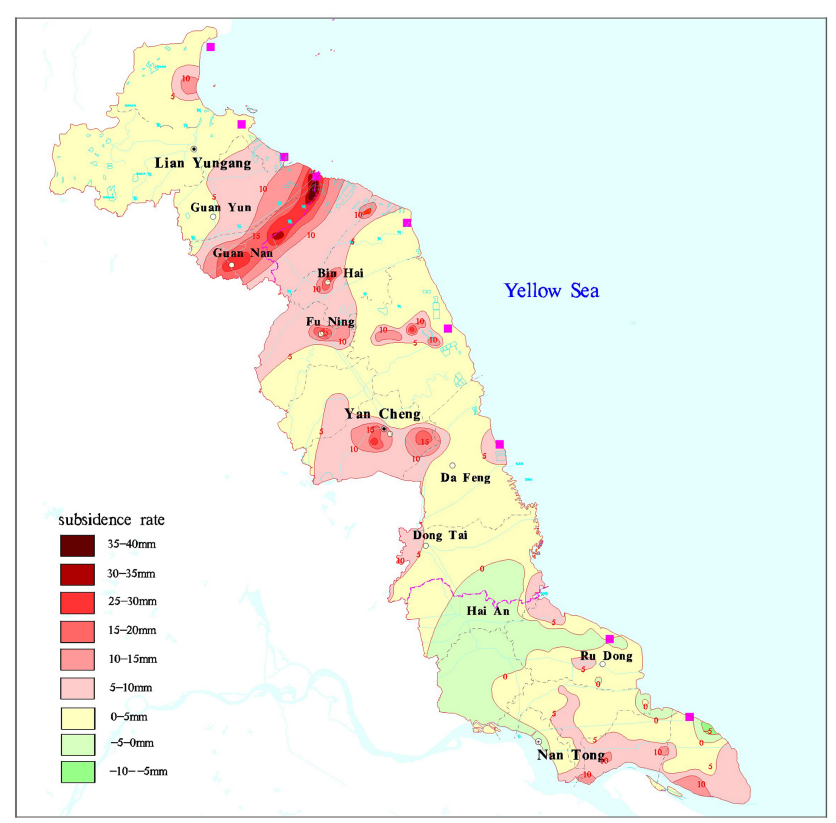

Figure 2. Subsidence rates in CAJS at the end of 2013.

ers of varying thickness generally have not finished selfconsolidation and may be associated with land subsidence (Zhang et al., 2007). The burial depth of bedrock in the urban district of central Yancheng City and south Dongtai County has exceeded $1000 \mathrm{~m}$. The compressible loose layers are thick and are easily susceptible to subsidence due to groundwater exploitation.

Neotectonic movement has resulted in pre-Quaternary topography featured by depression and uplift. The loose Quaternary deposits in the depressed areas are thicker than $300 \mathrm{~m}$, whereas the thickness of loose deposits is smaller in the uplifted region. Since the Quaternary, the frequent alternation of marine and terrestrial environments has led to the complex genesis of Quaternary deposits and interbedding of sand layers and clayey soil. Moreover, an obvious rhythmic deposition pattern has been noted, providing the material basis for land subsidence.

The thickness of loose layers in the middle and southern coastal areas of Jiangsu Province is greater than $1000 \mathrm{~m}$, and can even exceed $1400 \mathrm{~m}$ in the mid-regions and $1800 \mathrm{~m}$ in the southern regions (Fig. 3). Generally, four confined aquifers have been developed, indicating abundant groundwater resources. However, land subsidence is likely to occur due to groundwater overexploitation. For example, in Dafeng City and the urban district of Yancheng City, cumulative subsidence is greater than $700 \mathrm{~mm}$, mainly due to the thick loose layers. Although the loose deposits in northern coastal areas are less thick, the evidence still indicates that the land subsidence was due to the highly developed soft soil layers in the offshore zone. 


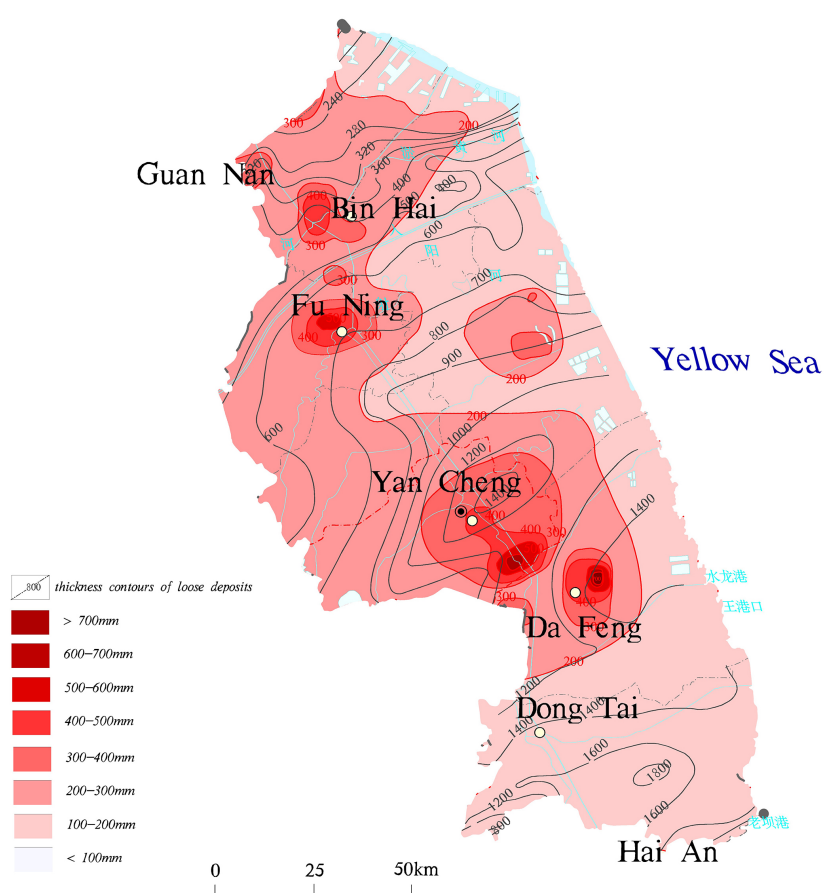

Figure 3. Relationships between cumulative land subsidence and the thickness of loose deposits from 1985 to 2013.

\subsection{Groundwater overexploitation as the main cause of land subsidence}

Land subsidence in the coastal areas of Jiangsu Province is closely related to groundwater exploitation with a high correspondence in time and space. Taking Nantong City as an example, before the 1980s, groundwater exploitation mainly occurred in Nantong City and the surrounding areas, leading to land subsidence in the urban district. After the 1990s, large-scale groundwater exploitation caused land subsidence throughout the entire region. The groundwater table has continuously declined along with the increase in exploitation, and the subsidence rate has risen as well.

The land subsidence cone basically overlaps the groundwater depression cone (Fig. 4). For example, along the banks of Guan River and in the urban districts of Yancheng and Nantong City, close spatial and temporal correlations between land subsidence and groundwater exploitations are clearly visible.

Land subsidence is jointly influenced by the compaction of the sand layer due to excess swabbing of the confined aquifer and deformation of the upper-confined bed and above due to water release by clayey soil. Land subsidence in coastal areas is controlled by the intensity of confined water exploitation. Earlier and more intensive exploitation corresponds with larger land subsidence. The subsidence rate is determined by the burial depth of the exploited groundwater layer and the physical properties of the aquifer and overlying aquitard.

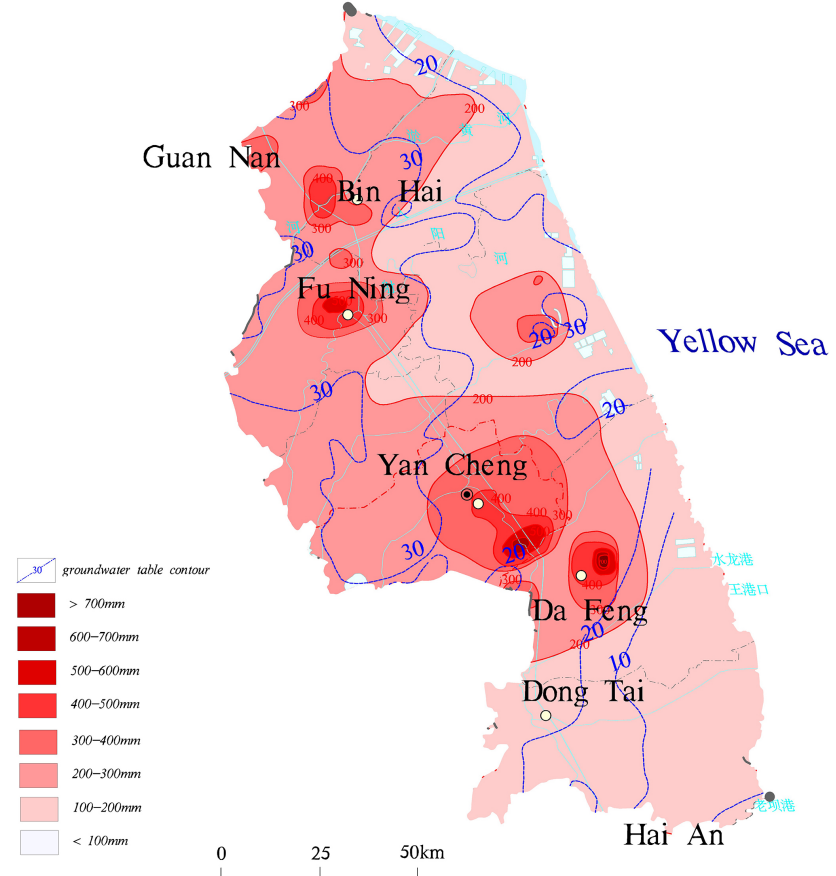

Figure 4. Relationships between subsidence rates and groundwater depression cone in 2013.

However, land subsidence is not completely coupled to the depression cone of confined water, and the water table depth has to be considered. It has been found that water table depth directly corresponds with subsidence. The intensification of groundwater exploitation increases the stress on the soil layers. The aquifer bears the largest stress, followed by the overlying confining units, with the disrupted equilibrium lying between upward water stress and soil-layer stress. Due to the higher compactness of the water-bearing sand layer compared with clayey soil, the sand layer has a smaller subsidence under compaction, whereas clayey soil has a greater subsidence. The intensification of groundwater exploitation will cause more strata to lose the equilibrium between water and soil stress. As a result, land subsidence will increase, and the relationship between the water table and subsidence will not be in equilibrium.

A relationship exists between the annual cumulative subsidence of the confined aquifer III (the main exploitation layer) and the overlying geological strata and changes in the water table of the confined aquifer III. It has been found that subsidence is higher under a continuously declining water table. When the amount of exploitation is under control (indicated by a rise in the water table), land subsidence decreases.

\subsection{Engineering and construction activities increase land subsidence}

Under the progress of coastal development and the construction of coastal cities and ports, the impacts of engineering 
facilities on land subsidence are increasing (e.g. high-rise buildings, expressways, high-speed railways, ports, water usage, and drainage pipes). Foundation pits are usually excavated either openly or underground, leading to obvious subsidence. This is particularly prominent in the large-scale tunnel excavation.

Land subsidence caused by engineering activities usually occurs locally in shallow strata affected by frequent and intense engineering activities. This is considerably distinguishable from the subsidence of regional and deep strata caused by groundwater exploitation. However, the contribution of engineering activities to total subsidence is increasing and can no longer be neglected.

Given the geological conditions of the coastal areas of Jiangsu Province, intensive groundwater exploitation activities have led to the formation of several large subsidence cones. Holocene soft soil in shallow strata is likely to consolidate and deform due to engineering activities. Thus, these coastal areas are facing the grim challenges of land subsidence due to multiple factors.

\section{Suggestions for the prevention and control of land subsidence}

\subsection{Establishment of a land-subsidence monitoring network}

In contrast to the cities of Suzhou, Wuxi, and Changshu in Jiangsu Province, the coastal areas have less intense engineering activities and more complicated geological conditions such as neotectonic activities, thick loose deposits, and more groundwater exploitation layers. Therefore, the mechanisms of land subsidence are more complicated. Due to the combined factors of low elevation and strong storm tides, land subsidence may pose greater danger. Therefore, it is necessary to build a land-subsidence monitoring network for coastal areas that includes GPS, bedrock markers, layerwise markers, dynamic groundwater monitoring, automated monitoring systems, and a land subsidence surveillance center.

\subsection{Establishment of multi-department linkage mechanisms}

Authorities in water conservancy, municipal administration, and construction agencies should coordinate their activities to enhance groundwater exploitation management and reverse the trend of increasing land subsidence. Municipal engineering and construction and land-use planning should fully consider the impacts of land subsidence. Caution should be exercised to strictly control land subsidence due to engineering in densely built areas (e.g. dewatering in deep foundation pits). Geotechnical investigations and foundation treatments should be properly conducted in soft-soil regions.

\section{References}

Hu, R. L., Yue, Z. Q., and Wang, L. C.: Review on current status and challenging issues of land subsidence in China, Eng. Geol., 76, 65-77, 2004.

Xu, Y. S., Shen, S. L., and Cai, Z. Y.: The state of land subsidence and prediction approaches due to groundwater withdrawal in China, Nat. Hazards, 45, 123-135, 2008.

Xue, Y. Q., Zhang, Y., and Ye, S. J.: Land subsidence in China, Environ. Geol., 48, 713-720, 2005.

Zhang, Y., Xue, Y. Q., Wu, J. C., Ye, S. J., Wei, Z. X., Li, Q. F., and Yu, J.: Characteristics of aquifer system deformation in the Southern Yangtze Delta, China, Eng. Geol., 90, 160-173, 2007. 